\title{
Intraparenchymal intracranial pressure monitoring for hydrocephalus and cerebrospinal fluid disorders
}

\author{
Aswin Chari ${ }^{1,2}$ - Debayan Dasgupta ${ }^{1} \cdot$ Alexander Smedley $^{1} \cdot$ Claudia Craven $^{1}$. \\ Edward Dyson $^{1} \cdot$ Samir Matloob $^{1} \cdot$ Simon Thompson $^{1} \cdot$ Lewis Thorne $^{1}$ • \\ Ahmed K. Toma ${ }^{1} \cdot$ Laurence Watkins ${ }^{1}$
}

Received: 15 March 2017 / Accepted: 19 July 2017 / Published online: 10 August 2017

(C) The Author(s) 2017. This article is an open access publication

\begin{abstract}
Background Elective intraparenchymal intracranial pressure (ICP) monitoring is useful for the diagnosis and treatment of hydrocephalus and cerebrospinal fluid (CSF) disorders. This retrospective study analyzes median ICP and pulse amplitude (PA) recordings in neurosurgically naïve patients undergoing elective ICP monitoring for suspected CSF disorders. Methods Retrospective review of prospectively collated database of neurosurgically naïve patients undergoing elective ICP monitoring for suspected hydrocephalus and CSF disorders. Following extraction of the median ICP and PA values (separated into all, day and night time recordings), principal component analysis (PCA) was performed to identify the principal factors determining the spread of the data. Exploratory comparisons and correlations of ICP and PA values were explored, including by post hoc diagnostic groupings and age. Results A total of 198 patients were identified in six distinct diagnostic groups ( $n=21-47$ in each).

The PCA suggested that there were two main factors accounting for the spread in the data, with $61.4 \%$ of the variance determined largely by the PA and $33.0 \%$ by the ICP recordings.

Exploratory comparisons of PA and ICP between the diagnostic groups showed significant differences between the groups. Specifically, significant differences were observed in
\end{abstract}

Aswin Chari

aswinchari@gmail.com

1 Victor Horsley Department of Neurosurgery, National Hospital for Neurology and Neurosurgery, Queen Square, London WC1N 3BG, UK

2 Division of Brain Sciences, Faculty of Medicine, Imperial College London, London, UK
PA between a group managed conservatively and the Chiari/ syrinx, IIH, and NPH/LOVA groups and in the ICP between the conservatively managed group and high-pressure, $\mathrm{IIH}$, and low-pressure groups. Correlations between ICP and PA revealed some interesting trends in the different diagnostic groups and correlations between ICP, PA, and age revealed a decreasing ICP and increasing PA with age.

Conclusions This study provides insights into hydrodynamic disturbances in different diagnostic groups of patients with CSF hydrodynamic disorders. It highlights the utility of analyzing both median PA and ICP recordings, stratified into day and night time recordings.

Keywords Intracranial pressure $\cdot$ Hydrocephalus · Cerebrospinal fluid dynamics

\section{Introduction}

The use of elective intraparenchymal intracranial pressure (ICP) monitoring for the diagnosis and management of hydrocephalus and cerebrospinal fluid (CSF) disorders in adults has been used for several years in a number of different centers $[9,10,20,21]$. It has multiple benefits over other diagnostic procedures such as lumbar puncture and lumbar infusion studies as it provides a longer period of monitoring, with opportunities to identify fluctuations isolated to certain periods of the day/night and track symptom-pressure correlations over a period of 24-48 $\mathrm{h}$ [19]. It reduces the risk of false positives and false negatives induced by 'snapshot' methods such as lumbar puncture. ICP monitoring also has the ability to assess response to interventions (such as CSF shunts and venous sinus stents) and has been shown to reduce the need for re-intervention in these patients [17, 18, 21]. In our 
experience, intraparenchymal ICP monitoring is safe, with a low rate of complications [5, 20, 21].

In our institution, elective ICP monitoring is undertaken in patients who have symptoms deemed consistent with altered CSF dynamics, following discussion at a specialist multidisciplinary team meeting consisting of neurosurgeons and neurologists with a specialist interest in headache, hydrocephalus, and CSF disorders. Following monitoring, the specialist multidisciplinary team arrives at a diagnosis, based upon a holistic assessment of the patient's symptoms and analysis of the ICP trace over the monitoring period, the ICP histogram and the ICP vs. PA scatter plot.

Despite the benefits and relatively low risk, there are little published data on the results of invasive ICP monitoring in this context, specifically data about values to guide clinical decisionmaking in both naïve patients undergoing ICP monitoring and patients undergoing ICP monitoring to assess dysfunction postinterventions such CSF shunts and venous sinus stents.

This study undertakes a retrospective analysis of the median ICP and pulse amplitude (PA) recordings measured during the entire recording phase (all), day time (day), and night time (night) in this cohort of patients undergoing intraparenchymal ICP monitoring for suspected hydrocephalus and disorders of CSF dynamics. The aims of the study were to assess, via principal component analysis (PCA), which of these components are critical to the interpretation. Previous work from our center has suggested that 24-h monitoring is sufficient [19] and splitting the data into day time and night time would also allow us to assess whether overnight monitoring is required to make a diagnosis.

\section{Methods}

A prospectively maintained database of recordings of all adult patients undergoing elective intraparenchymal ICP monitoring was retrospectively reviewed to identify all episodes of intracranial pressure monitoring undertaken at our institution between June 2006 and December 2015.

Inclusion criteria:

- Patients undergoing elective diagnostic ICP monitoring who were naïve to previous neurosurgical intervention

Exclusion criteria:

- Previous neurosurgical intervention that might have altered CSF dynamics

- Multiple episodes of ICP monitoring for that patient

- Post-ICP monitoring diagnosis unavailable from retrospective review of patient notes

All patients underwent ICP monitoring following a multidisciplinary decision. This involved the insertion of a Spiegelberg intraparenchymal ICP probe under either sedation or local anesthesia under strict aseptic conditions in an operating theatre, as part of a specialist CSF disorder neurosurgical team. Following insertion, patients were admitted to the neurosurgical ward and connected to a monitor and a computer and the data were recorded via a specialized software package, ICM+, which subtracts artefacts and records minute-by-minute data on ICP and PA. Patients were managed in a protocolized fashion, being allowed to sit up (in bed or in a chair) and mobilize during the day time and lay in bed at night. Monitoring continued for 24$48 \mathrm{~h}$ until the treating neurosurgical team deemed the recording to be of sufficient quality. Patients were then discharged.

Following recording, the data were analyzed using an inhouse analysis tool, which isolated the median ICP and PA during the whole recording period (all), day and night times. The tool also calculated an indirect measure of compliance and had graphical representations of the distribution of ICP and a correlation between ICP and PA during the recording period (Fig. 1). The diagnosis was then determined by a specialist multidisciplinary team consisting of specialist neurosurgeons and neurologists; the team considered the clinical picture as well as the results of the ICP monitoring, including ICP trace over the monitoring period, the ICP histogram, and the ICP vs. PA scatter plot.

Following collection for this study, data were analyzed using Microsoft Excel and IBM SPSS Statistics v24. Principal component analysis (PCA) was conducted to assess the principal components of the data set. Descriptive analyses and correlations were explored to assess differences between the diagnostic groups.

\section{Results}

A total of 198 patients were identified who underwent firsttime ICP monitoring over the study period who were naïve to prior neurosurgical intervention. The population demographics, split by diagnosis, are shown in Table 1. Diagnoses were split into broad categories and are described in the table. The population was diverse in terms of age, ranging from 16 to 85 (Fig. 2a), with a good range of age groups in each of the diagnostic subgroups (Fig. 2b).

\section{Principal component analysis}

PCA was conducted on six variables (median ICP and PA, split into all, day and night) following adequate tests for sampling adequacy (Kaiser-Meyer-Olkin measure $=0.658$ ) and sphericity (Bartlett's test, $p<0.001$ ). This analysis did not take into account the post hoc diagnostic groups. The scree plot suggested two principal components with an Eigen value $>1$. These normalized factors were largely determined by the three PA values (factor 1) and the three ICP values (factor 2), as shown below. Factor 1 accounted 


\begin{tabular}{|c|c|c|c|c|c|c|c|c|c|c|c|}
\hline Time period & $\begin{array}{r}\text { Median } \\
\text { Sys } \\
\end{array}$ & Median Dias & $\begin{array}{r}\text { Median } \\
\text { ICP }\end{array}$ & $\begin{array}{r}\text { Median } \\
\text { Pulse } \\
\text { Amp } \\
\end{array}$ & Peak ICP & $\begin{array}{r}\text { Trough } \\
\text { ICP }\end{array}$ & $\begin{array}{r}\text { \%age } \\
\text { Negative } \\
\text { ICP } \\
\end{array}$ & $\begin{array}{l}\text { No ICP } \\
\text { spikes } \\
>25 / h r\end{array}$ & $P>15$ & PIP & $\begin{array}{rr}\text { Indirect } & \text { greatest } \\
\text { com- } & \mathrm{x} \text { hour } \\
\text { pliance } & \text { variance }\end{array}$ \\
\hline All & 7.7 & 5.3 & 6.635 & 3.3 & 22.55 & -18.9 & $43 \%$ & 0 & $8 \%$ & -0.348 & N/A $6 h-0.54$ \\
\hline Day & -5.4 & -9 & -7.2 & 3.3 & 18 & -14.65 & $81 \%$ & 0 & $3 \%$ & -0.392 & N/A $3 h-0.709$ \\
\hline Night & 14.3 & 11.1 & 12.61 & 3.3 & 20.2 & -3.7 & $0 \%$ & 0 & $12 \%$ & -0.269 & N/A \\
\hline Optional & -3.2 & -6.6 & -4.97 & 3.3 & 18 & -16.65 & $63 \%$ & 0 & $3 \%$ & -0.482 & $N / A$ \\
\hline
\end{tabular}
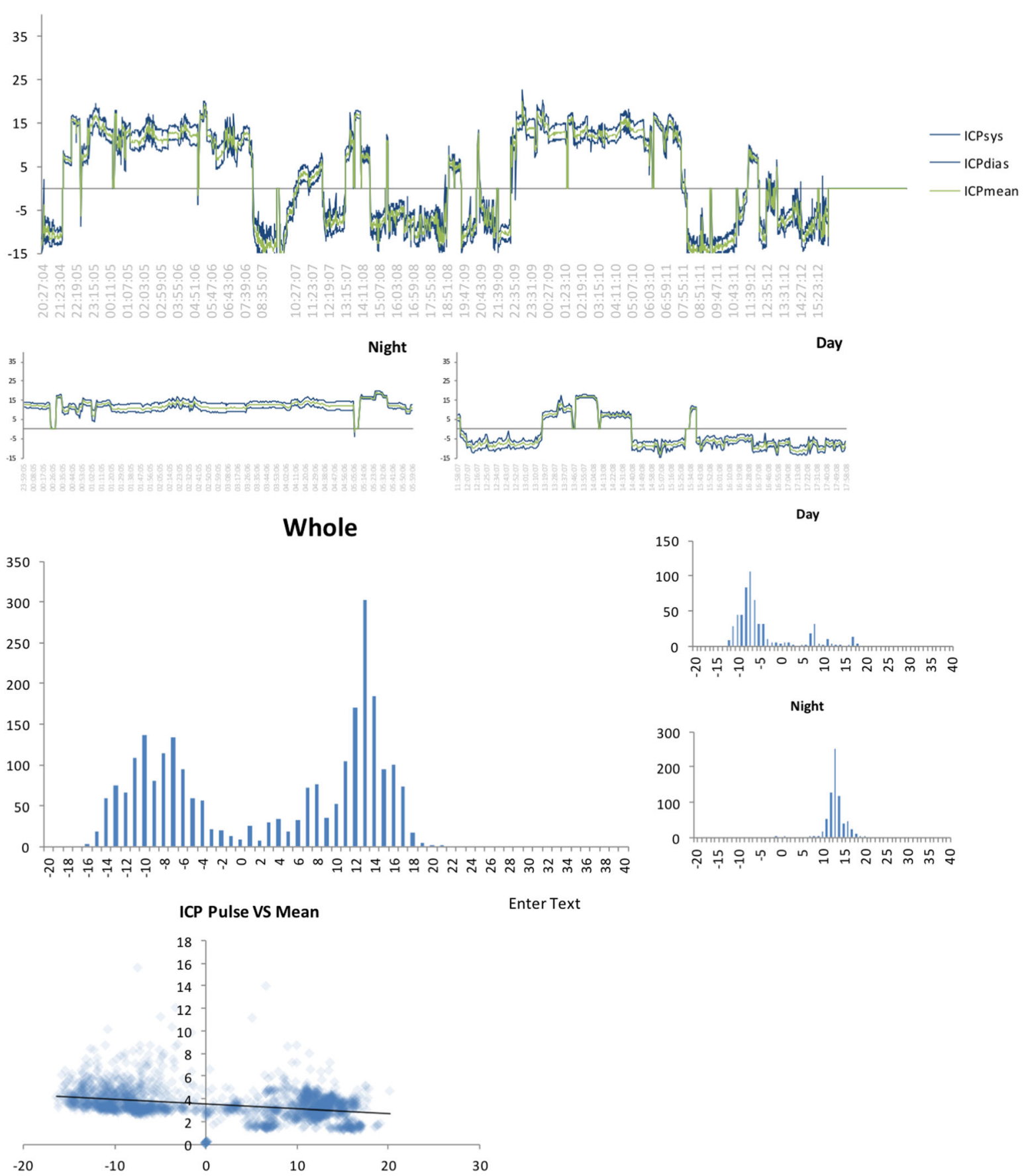

Enter Text

Fig. 1 Example of in-house analysis tool used to analyze ICP recordings for each patient 
Table 1 Diagnoses and demographic details of patients undergoing ICP monitoring

\begin{tabular}{|c|c|c|c|c|}
\hline Diagnosis & $n$ & $\begin{array}{l}\text { Mean } \\
\text { age }\end{array}$ & SD & Explanation of diagnosis \\
\hline $\begin{array}{c}\text { Conservatively } \\
\text { managed }\end{array}$ & 41 & 42.8 & 13.9 & $\begin{array}{l}\text { Likely to have a primary headache disorder. Further management } \\
\text { was overseen by a specialist headache neurologist }\end{array}$ \\
\hline Chiari/syrinx & 21 & 36.0 & 15.8 & $\begin{array}{l}\text { Patients with a Chiari I malformation and/or syrinx that were deemed } \\
\text { to be symptomatic from this }\end{array}$ \\
\hline $\begin{array}{l}\text { High-pressure } \\
\text { state }\end{array}$ & 37 & 41.3 & 13.5 & $\begin{array}{l}\text { High-pressure states included congenital, post-traumatic, } \\
\text { post-infectious, post-hemorrhagic hydrocephalus }\end{array}$ \\
\hline IIH & 35 & 34.9 & 11.2 & Idiopathic intracranial hypertension \\
\hline $\begin{array}{l}\text { Low-pressure } \\
\text { state }\end{array}$ & 37 & 50.8 & 12.7 & $\begin{array}{l}\text { Patients with a low-pressure state were investigated and/or had } \\
\text { treatment for spontaneous/iatrogenic CSF leaks }\end{array}$ \\
\hline NPH/LOVA & 27 & 55.7 & 21.4 & $\begin{array}{l}\text { Normal-pressure hydrocephalus or longstanding overt } \\
\text { ventriculomegaly in adults }\end{array}$ \\
\hline
\end{tabular}

for $61.4 \%$ of the variance in the and factor 2 accounted for $33.0 \%$ of the variance in the data.

Factor $1=0.984(\mathrm{PA}($ all $))+0.956(\mathrm{PA}($ day $))+0.953$ $(\mathrm{PA}$ (night) $)+0.134(\mathrm{ICP}$ (all) $)+0.137(\mathrm{ICP}$ (day) $)+$ 0.172 (ICP (night)).

Factor $2=0.146(\mathrm{PA}($ all $))+0.133(\mathrm{PA}($ day $))+0.166$ $(\mathrm{PA}$ (night) $)+0.980(\mathrm{ICP}$ (all) $)+0.949(\mathrm{ICP}$ (day) $)+$ 0.939 (ICP (night)).

A scatter plot of the factors, separated by post hoc diagnostic groups suggested separation of the diagnostic groups, with the 'conservatively managed' group towards the middle of the normalized data (Fig. 3).

\section{Descriptive analysis of diagnostic groups}

The PCA suggests that all six variables play a major role in separating the data into its principal components with the PA readings constituting factor 1 and the ICP readings constituting factor 2. To explore these relationships further, a descriptive analysis of the data was carried out, based on the post hoc diagnostic groupings.

Mean recordings of the median PAs (all, day, and night) and median ICPs (all, day, and night) for the patients in each diagnostic group are shown in Figs. 4 and 5, respectively. Independent-sample Kruskal-Wallis test showed significant differences between the different diagnostic groups in all six paradigms. Post hoc two-way heteroscedastic $t$ tests were performed with a Bonferroni correction ( $p=0.01$ as five tests were performed for each paradigm, comparing each group with the 'conservatively managed' group; significant results are indicated on the figures $(*)$. These indicate median PA values were significantly different between the 'conservatively managed' group and the Chiari/syrinx (all and day, but not night), IIH (all, day, and night) and NPH/LOVA (all, day, and night) groups. Median ICP values were significantly different between the 'conservatively managed' group and groups diagnosed with IIH (all, day, and night), high-pressure states (all, day, and night) and low-pressure states (all and day, but not night).

\section{Correlations between ICP, PA, and age}

To explore the data further, correlations were explored between ICP and PA and age. Regression curves were constructed using locally weighted scatter plot smoothing (LOESS regression) with the smoothing parameter, $\alpha$, set at $90 \%$. This method was chosen as an exploratory analysis as the relationship between the variables was not known.

Assessment of the relationship between ICP and PA (Fig. 6), stratified by diagnostic subgroups, revealed a relatively flat relationship between ICP and PA for the conservatively managed and low-pressure cohorts, with a linear direct relationship for the IIH and high-pressure state cohorts. The relationship for the Chiari/syrinx and NPH/LOVA cohorts revealed an interesting trend with PA initially rising with ICP (until a median ICP of around $5 \mathrm{mmHg}$ ) and then decreasing, revealing perhaps a more complex physiology in these mainly compliance-associated pathologies.

Assessment of ICP and PA changes with age in the whole cohort (Fig. 7a and b respectively) revealed a slow decrease in ICP and increase in PA with increasing age, although interpretation of this is limited due to the confounds of different age distributions of the pathologies investigated (Fig. 2b).

\section{Discussion}

We present the results of the largest series of intraparenchymal ICP monitoring in adult patients suspected of having disorders of CSF pressure and compliance who were naïve to neurosurgical intervention. The results provide valuable information about the disturbances in ICP and PA both in health and disease.

\section{Insight into ICP and PA in states of disease}

The PCA extracted two factors with an eigenvalue $>1$, indicating two principal components to the data set. The first factor, incorporating all three median PA readings, accounts for 


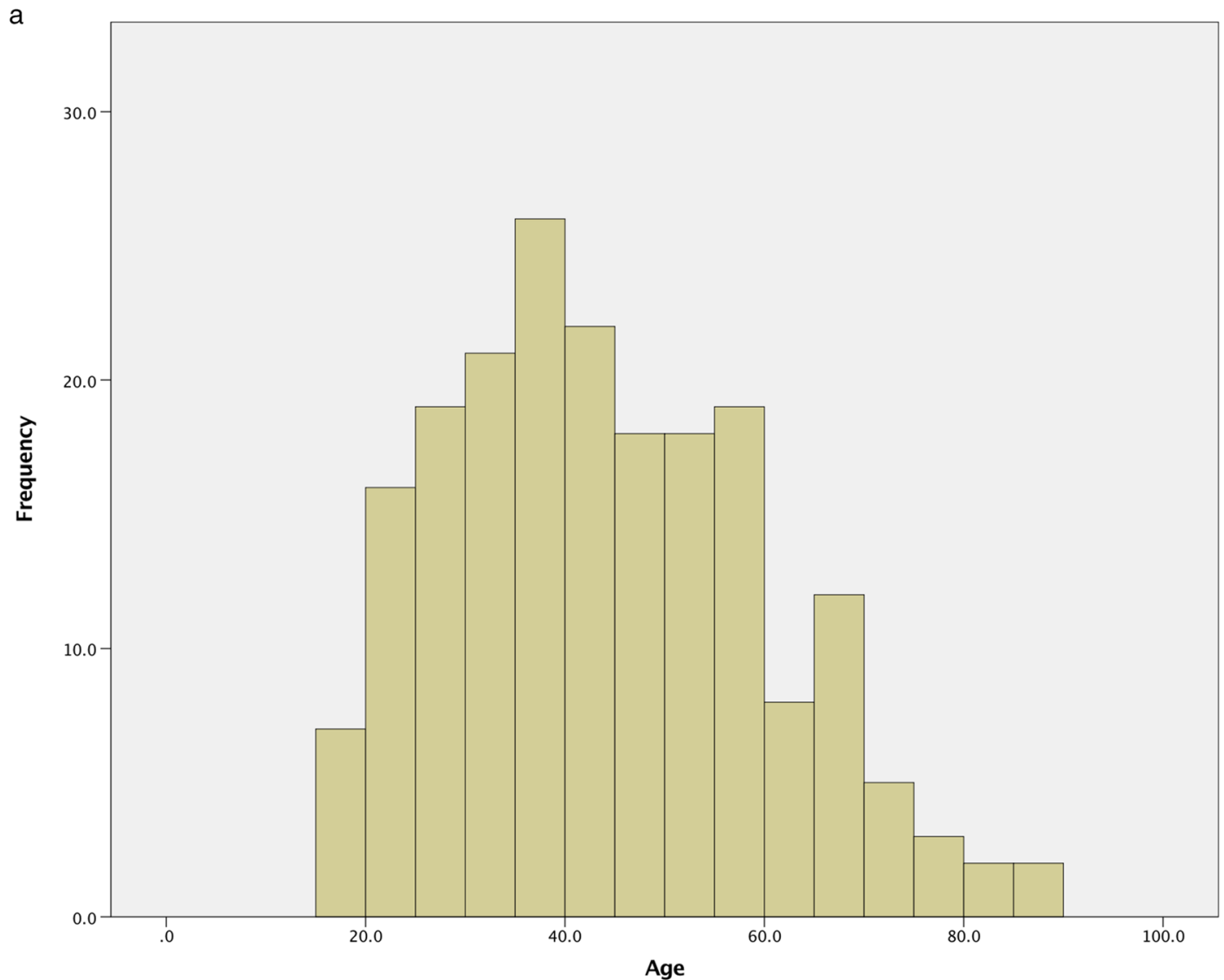

b

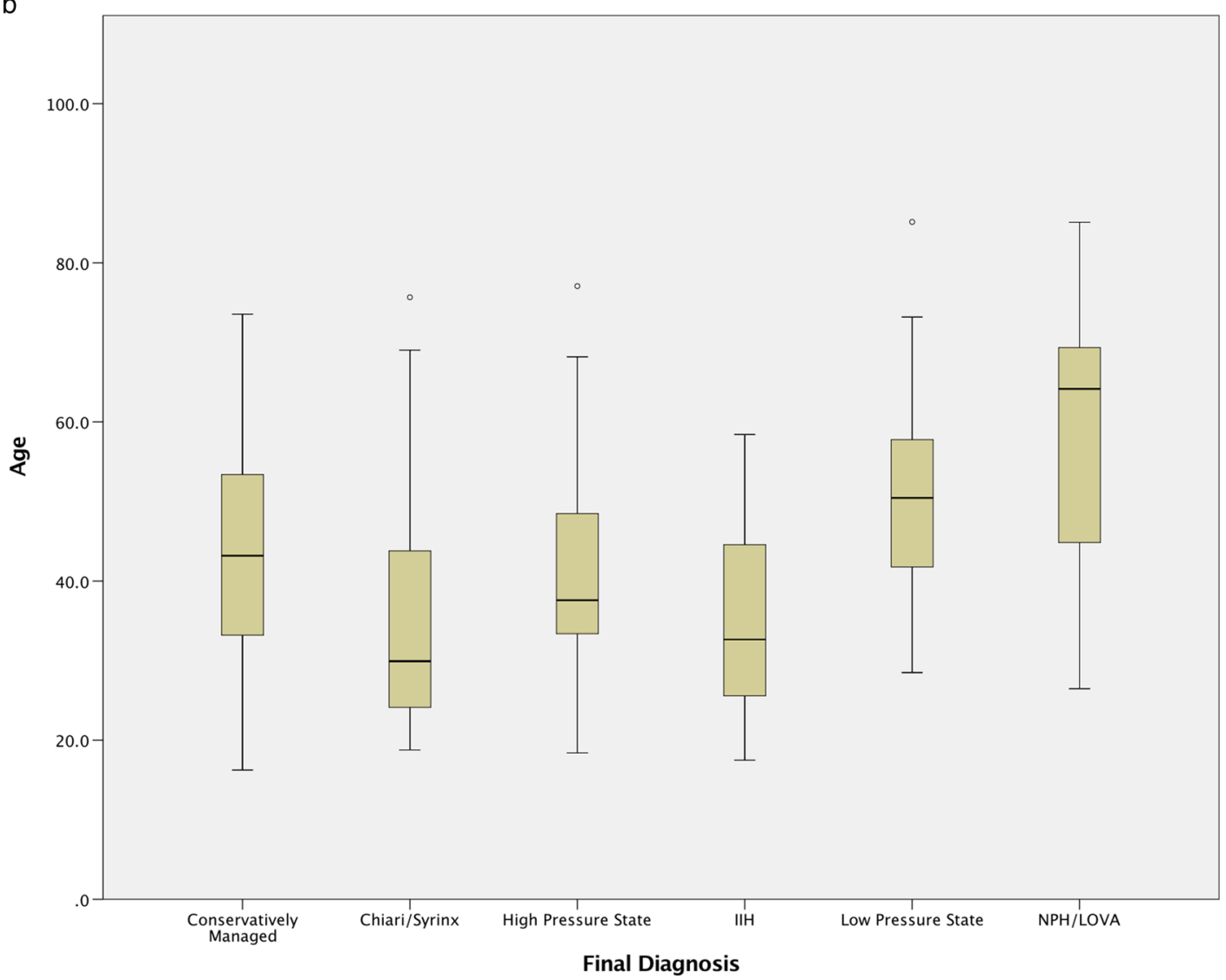


Fig. 2 Age distribution of patients undergoing ICP monitoring. The histogram (a) shows the wide range of ages undergoing ICP monitoring. The box plot (b) shows, as expected, a younger population undergoing monitoring for Chiari/syrinx and $\mathrm{IIH}$ and an older population undergoing monitoring for $\mathrm{NPH} / \mathrm{LOVA}$

almost two-thirds of the variance in the data and the second factor, incorporating all three median ICP readings, accounts for almost one-third of the variance in the data. This indicates that PA measurement might play a more important role in separating the data than ICP measurement, but that both contribute significantly to the overall spread in the data.

On exploratory descriptive analysis, significant differences were observed between the PA values in the conservatively managed group and the $\mathrm{IIH}$, Chiari/syrinx and NPH/LOVA groups (Fig. 4). These findings fit with the findings of other studies that show Chiari malformations and NPH/LOVA to be primarily disorders of CSF pulsatility and compliance [8, 11-15, 20, 21]. There was a trend towards significance in the PA for the high-pressure group; it may be hypothesized that this is due to the heterogeneous nature of this diagnostic group, encompassing a number of etiologies (including post-infectious, posthemorrhagic, and congenital), some of which may be associated with relatively normal intracranial compliance. Interestingly, the PAs were not different between the conservatively managed group and low-pressure groups, as would be predicted by the intracranial volume-pressure curves.

Significant differences were observed in the median ICP values between the conservatively managed group and those with high-pressure states, low-pressure states, and IIH (Fig. 5). Interestingly, the median ICP was no different between the low-pressure state and conservatively managed

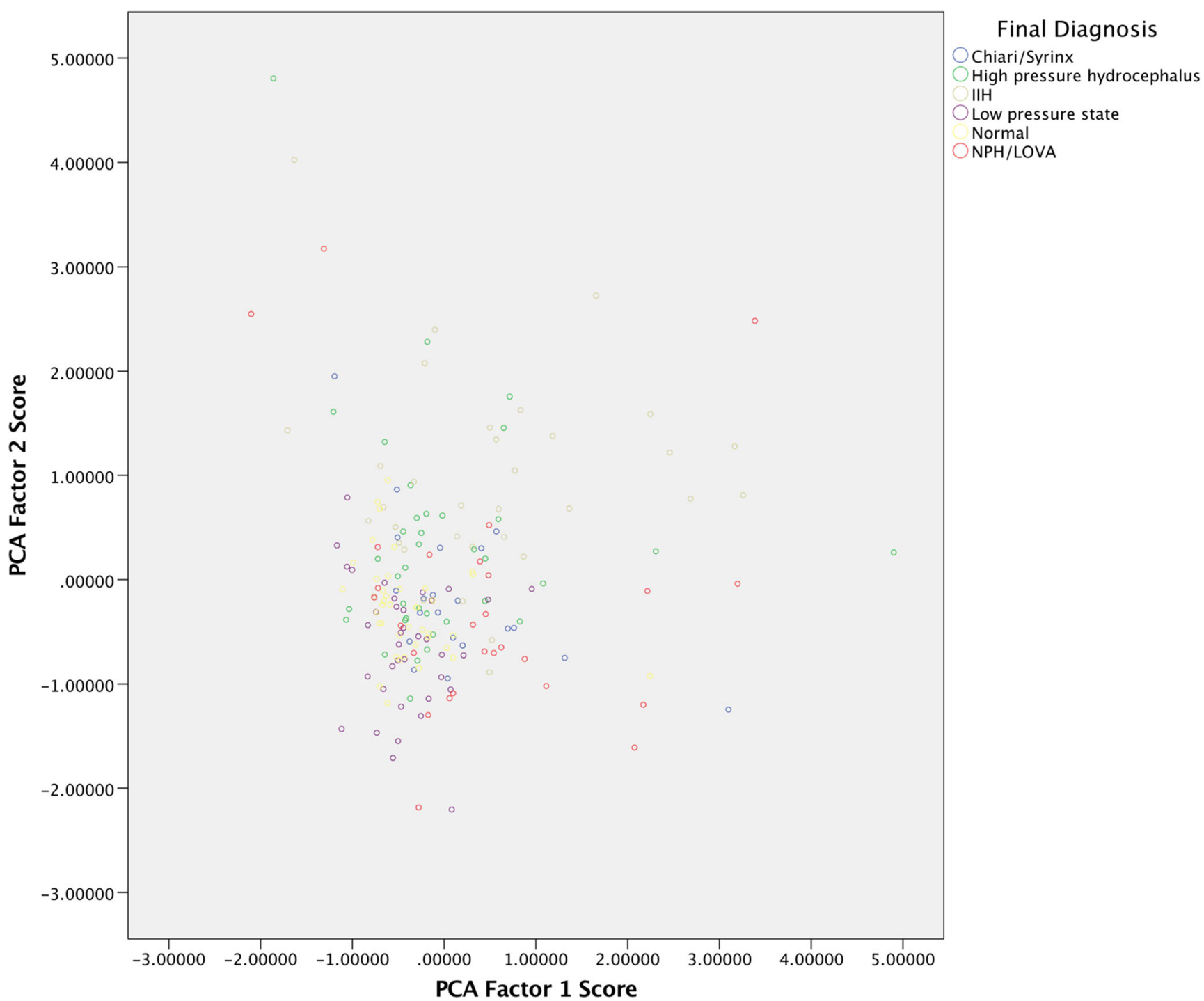

Fig. 3 Scatter plot based on the normalized scores from factors determined by the PCA. Each dot represents one patient and each post hoc diagnostic is assigned a different color 


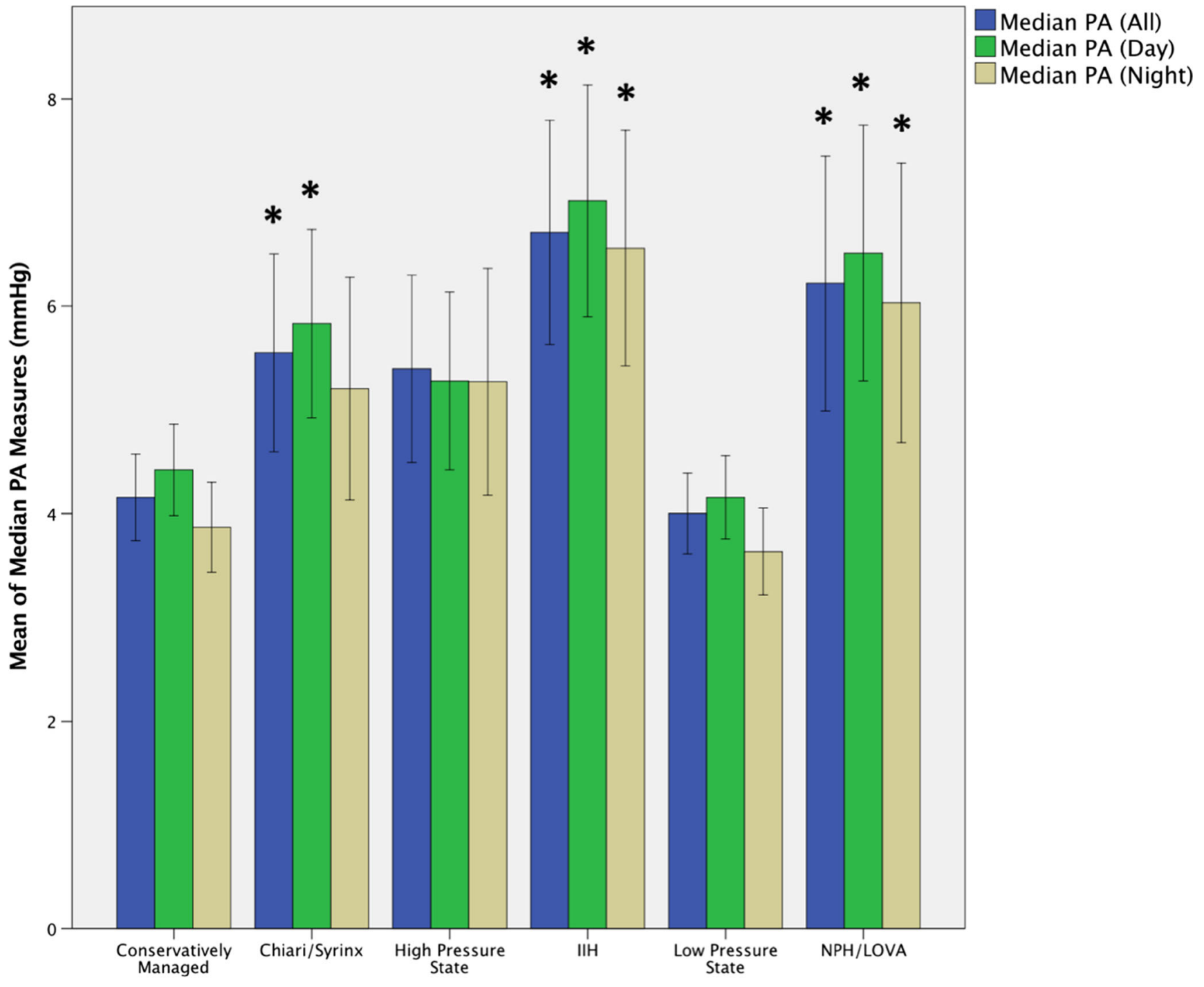

Final Diagnosis

Fig. 4 Mean recordings for median PA (all, day, and night) for the different post hoc diagnostic groups. Error bars denote 95\% confidence intervals. * indicates a statistically significant difference between the diagnostic category and the conservatively managed group

groups at night, perhaps due to redistribution of CSF associated with the supine population. There was no difference in the median ICPs between the conservatively managed and the Chiari/syrinx and NPH/LOVA groups, as would be expected from the etiologies and pathogeneses of the respective conditions.

Assessment of correlations between ICP and PA revealed some interesting trends. The differences in the regression curves between the conservatively managed cohort and the IIH and high-pressure state cohorts were expected and can be explained by a decrease in compliance in these conditions, even at low ICP values, and advocates for the measurement of $\mathrm{PA}$ as a marker of compliance in addition to ICP. The regression curves generated for the Chiari/syrinx and NPH/LOVA cohorts are somewhat more complex, with decreasing compliance beyond a certain ICP threshold of about $5 \mathrm{mmHg}$. This is more difficult to explain from a mechanistic perspective and perhaps accounts for the complex pathophysiology of these conditions. It remains to be seen if this relationship is true for individual patients and, importantly, in predicting treatment success in these patients.

\section{Insight into ICP and PA in healthy individuals}

Analysis of the conservatively managed group also provides valuable insights into the physiology and dynamics of CSF in 'normal' individuals. Given the ethical issues surrounding monitoring ICP in normal individuals, few studies have attempted to establish the hydrodynamics of CSF in normal individuals. Previous studies have sought to establish these normal values by measuring ICP in patients following excision of small, well-demarcated brain tumors [1-3]. Although 


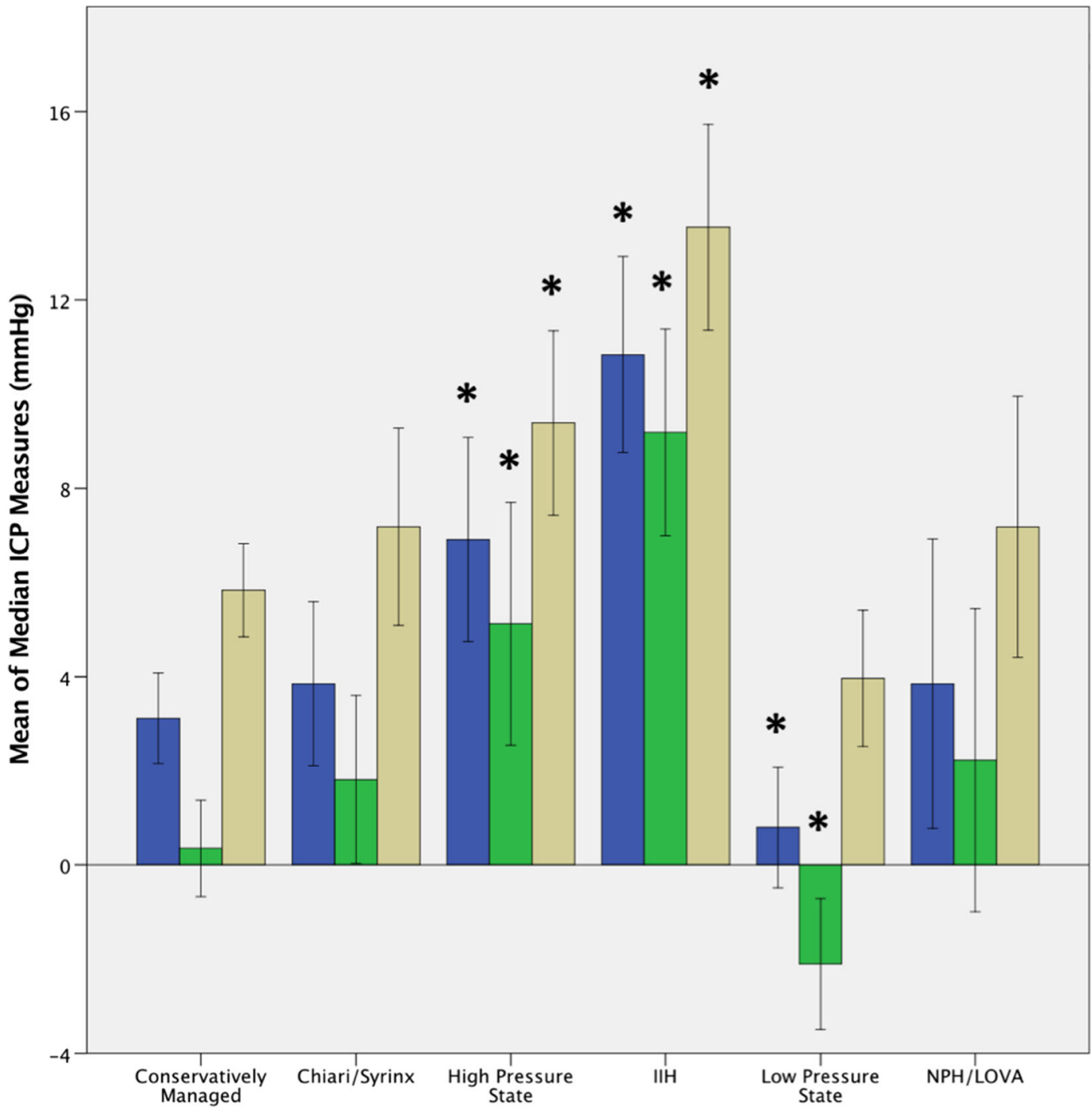

Final Diagnosis

Fig. 5 Mean recordings for median ICP (all, day, and night) for the different post hoc diagnostic groups. Error bars denote $95 \%$ confidence intervals. * indicates a statistically significant difference between the diagnostic category and the conservatively managed group

these studies have provided insight into ICP in healthy states, this is the first study to provide such data for pulse amplitudes. Although there are clear limitations with considering this preselected cohort of patients as entirely normal given the fact that they were chosen to undergo ICP monitoring because of their symptoms and the post hoc nature of their diagnoses, some insights may be drawn from these data.

Firstly, median ICP in this population was $3.21 \mathrm{mmHg}(95 \%$ CI 2.29-4.13), with this being lower during the day $(0.36 \mathrm{mmHg}, 95 \% \mathrm{CI}-0.62-1.34)$ and higher at night (5.84 $\mathrm{mmHg}$, 95\% CI 4.90-6.78), as expected by the change in posture. These values differ greatly from the accepted 'normal range' during a supine lumbar puncture but agree broadly with the other studies in this field [1-3]; Andresen and colleagues measure mean ICP (rather than median ICP) following removal of a small tumor and found pressures to be
$0.5 \pm 4.0 \mathrm{mmHg}$ in the supine position and $-3.7 \pm 3.8 \mathrm{mmHg}$ in the standing position [3]. The median pulse amplitudes also follow a similar trend, with median PA being $4.12 \mathrm{mmHg}$ (95\% CI 3.72-4.52) during the recordings, higher during the day (4.42 mmHg, 95\% CI 4.00-4.84) and lower during the night (3.84 mmHg, 95\% CI 3.43-4.25).

We also acknowledge that the recorded values are vastly different to the values and thresholds used in the sphere of traumatic brain injury (TBI) $[6,7,16]$ but hypothesize that this can be explained by the chronicity of the rise in these disorders, compared to the acute rises seen in TBI.

\section{Insight into changes in ICP and PA with age}

The changes in ICP and PA with age elucidated in this study are also of interest. The trend suggests that ICP slowly 


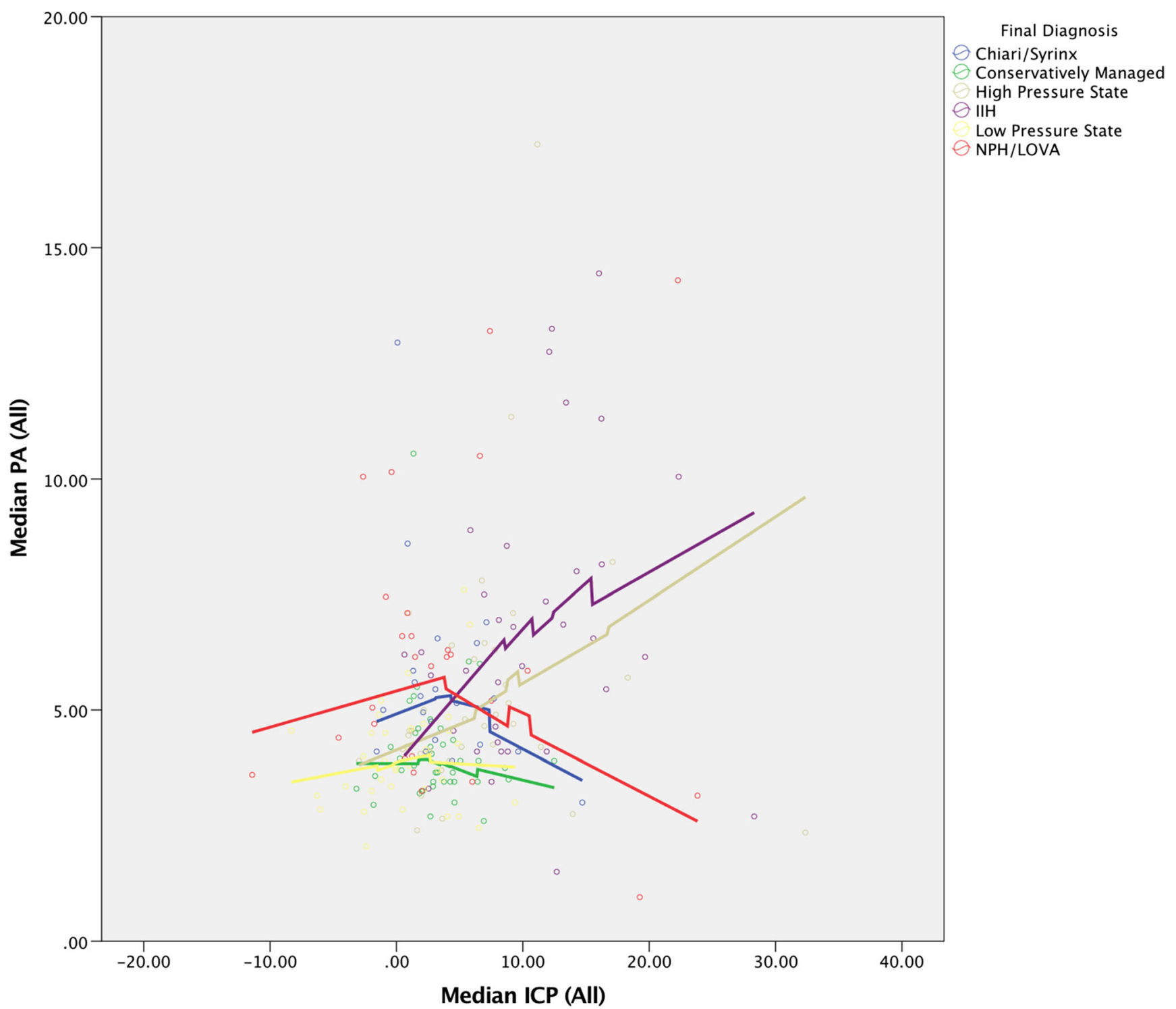

Fig. 6 Correlation between ICP and PA, stratified by the diagnostic groups. Lines represent locally weighted scatter plot smoothing (LOESS) regression curves with the smoothing parameter, $\alpha$, set at $90 \%$

decreases with age and PA slowly increases with age. These findings must be interpreted cautiously due to the selection bias of the patients in this study. The findings could be explained by age-associated atrophy, or the fact that the age distribution for patients being investigated for conditions like $\mathrm{IIH}$ and high-pressure states were younger than those being investigated for conditions like NPH.

\section{Limitations of the study}

This study has a number of limitations. It is retrospective and therefore subject to all the biases associated with retrospective studies. Perhaps the most important limitation, however, is the comparison group, designated as the conservatively managed group. These were patients chosen by a specialist multidisciplinary team to undergo ICP monitoring due to symptoms that could have been consistent with disorders of CSF dynamics; they were diagnosed as likely having a primary headache disorder postmonitoring by the same multidisciplinary team, and therefore used as a comparison group to provide insight into 'normal' CSF dynamics. There is clearly a circular nature to this diagnosis. However, given the ethical implications of undertaking invasive ICP monitoring in normal asymptomatic individuals, this may be the closest next-best alternative. In addition, the PCA conducted in this study was independent of the post hoc diagnostic groupings, suggesting that a composite of the median PA and ICP measures account for the variance in the data.

Another limitation is the fact that only median measures were used. This was due to the historical nature of the data and the lack of raw data for the older recordings. More in-depth analysis using minute-by-minute data for each patient is warranted. In addition, further analyses accounting for postural 
a

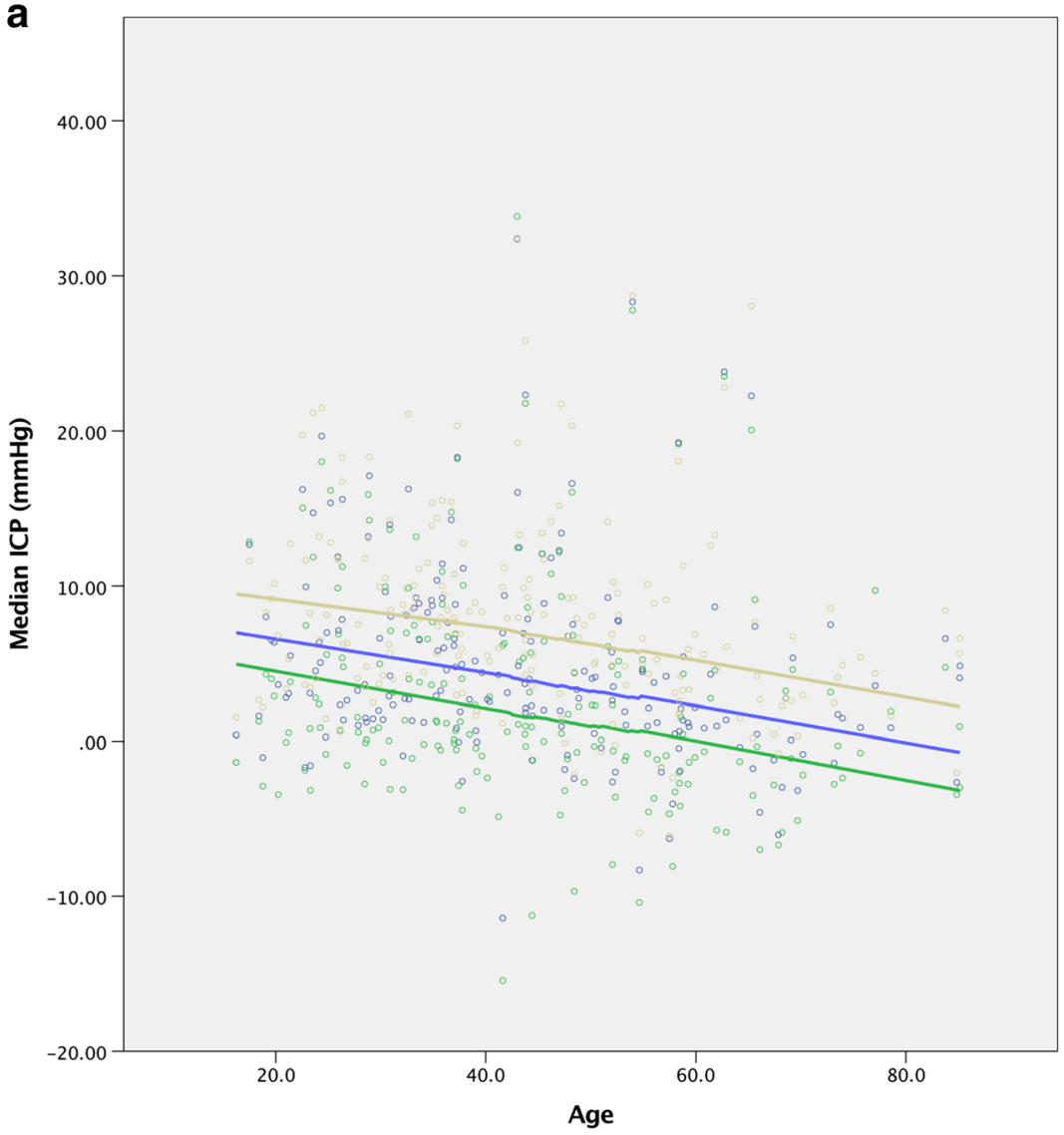

b

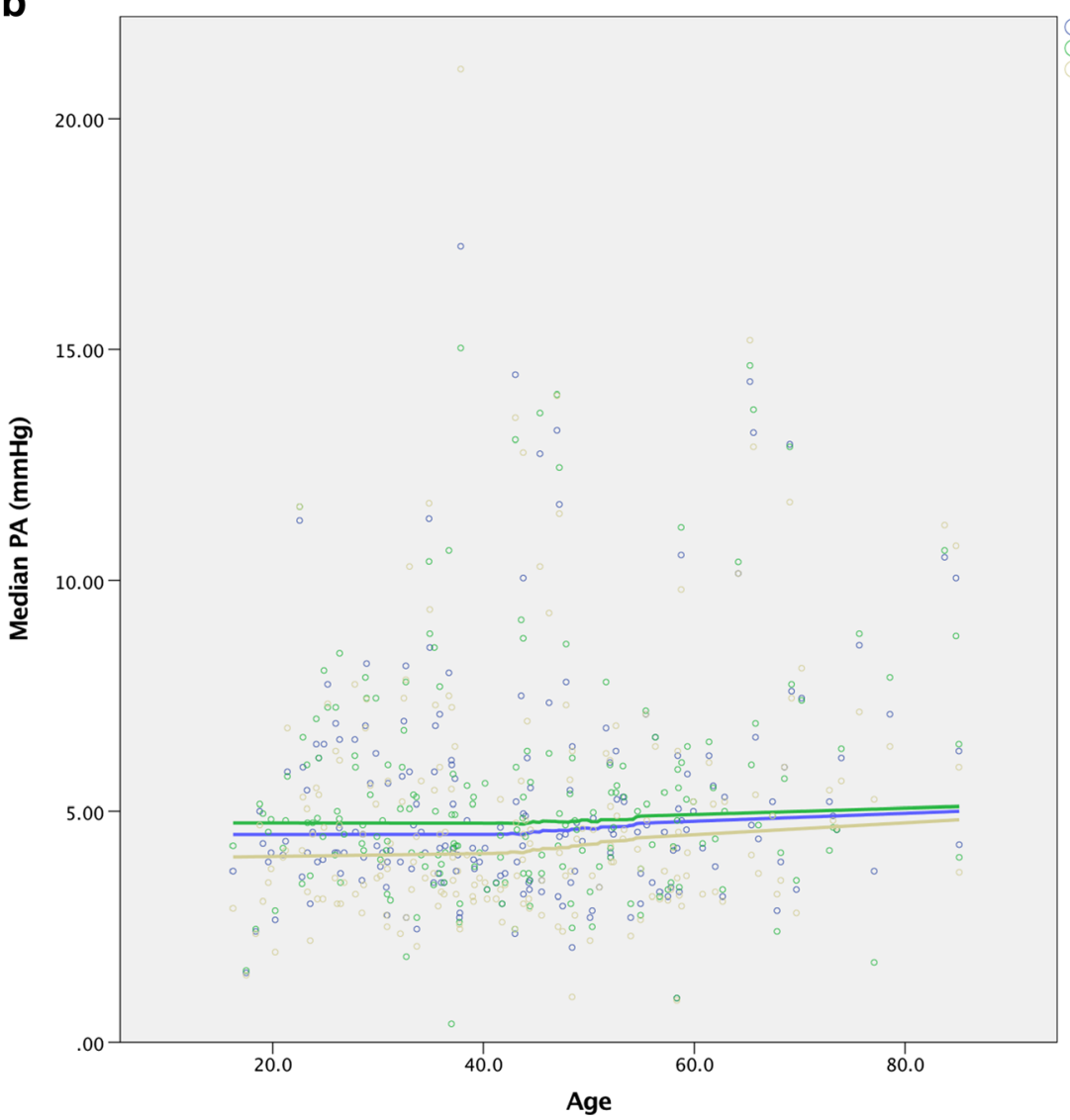

Age - Median ICP (All)

Age - Median ICP (Day)

Age - Median ICP (Night)
Age - Median PA (All) Age - Median PA (Day) Age - Median PA (Night) 
4 Fig. 7 Changes in ICP (a) and PA (b) with age in the population. Lines represent locally weighted scatter plot smoothing (LOESS) regression curves with the smoothing parameter, $\alpha$, set at $90 \%$

changes using an accelerometer and studying the withinpatient correlations between ICP and PA over the monitoring period will prove invaluable in elucidating the pathophysiology of these complex disorders.

\section{Future directions}

These findings are an important stepping stone to allow a more nuanced use of ICP monitoring for the diagnosis and management of hydrocephalus and CSF disorders. The next step would involve the development of thresholds for each diagnostic category and prospective validation of these thresholds based on the recording results, blinded to the clinical and radiological information.

Future work also needs to focus on a more detailed interrogation of the recordings, by analyzing the spread of minuteby-minute ICP and PA recordings and utilizing these detailed data to assess symptom-pressure correlations. In addition, future analyses need to build on the work of Andresen and colleagues to formulate a more detailed understanding of the relationship between posture and ICP [2]. Analyzing individual patient ICP-PA correlations may also aid the understanding of the differences between individuals, both in health and disease, with the aim of achieving optimum personalized ICP and PA targets for individuals where intracranial pressure and compliance are normalized.

\section{Conclusions}

This study gives us insight into median ICP and PA measures in health and disease for a large cohort of patients undergoing ICP monitoring for suspected disorders of CSF dynamics. It serves as a platform for more in-depth analyses in the future and acts as a useful benchmark for the evaluation of untreated and treated patients for guided management of hydrocephalus and CSF disorders. In combination with detailed knowledge of the hydrodynamic properties of shunts [4], these data may allow us to achieve the goal of restoring 'normal' CSF hydrodynamics in these patients.

\section{Compliance with ethical standards}

Funding No funding was received for this research.

Conflict of interest All authors certify that they have no affiliations with or involvement in any organization or entity with any financial interest (such as honoraria; educational grants; participation in speakers' bureaus; membership, employment, consultancies, stock ownership, or other equity interest; and expert testimony or patent-licensing arrangements), or non-financial interest (such as personal or professional relationships, affiliations, knowledge or beliefs) in the subject matter or materials discussed in this manuscript.

Ethical approval All procedures performed in studies involving human participants were in accordance with the ethical standards of the institutional and/or national research committee and with the 1964 Helsinki Declaration and its later amendments or comparable ethical standards. For this type of study formal consent is not required.

Informed consent For this type of study formal consent is not required.

Competing interests The authors confirm that there are no competing interests to declare.

Authorship statement All authors have met ICMJE criteria for authorship. AC, LT, AKT, and LW conceived the study; AC, DD, AS, CC, ED, SM and ST collected the data; AC, CC, and AKT analyzed the data; AC drafted the manuscript, and all authors edited the manuscript. All authors have reviewed and approved the final version of the manuscript prior to submission. AC is the guarantor.

Open Access This article is distributed under the terms of the Creative Commons Attribution 4.0 International License (http:// creativecommons.org/licenses/by/4.0/), which permits unrestricted use, distribution, and reproduction in any medium, provided you give appropriate credit to the original author(s) and the source, provide a link to the Creative Commons license, and indicate if changes were made.

\section{References}

1. Andresen M, Hadi A, Juhler M (2016) Evaluation of intracranial pressure in different body postures and disease entities. Acta Neurochir Suppl 122:45-47

2. Andresen M, Hadi A, Petersen LG, Juhler M (2015) Effect of postural changes on ICP in healthy and ill subjects. Acta Neurochir 157:109-113

3. Andresen M, Juhler M (2014) Intracranial pressure following complete removal of a small demarcated brain tumor: a model for normal intracranial pressure in humans. J Neurosurg 121:797-801

4. Chari A, Czosnyka M, Richards HK, Pickard JD, Czosnyka ZH (2014) Hydrocephalus shunt technology: 20 years of experience from the Cambridge Shunt Evaluation Laboratory. J Neurosurg 120 https://www.ncbi.nlm.nih.gov/pubmed/24405071

5. Chari A, Dyson EW, Stevens AR, Thompson SD, Craven C, Matloob SA, Chan HW, Shah SN, Mostafa T, Patel NA, Ekanayake J, Haylock-Vize P, Toma AK, Watkins LD (2015) Three-hundred cases of Spiegelberg ICP monitoring for hydrocephalus and CSF disorders: the queen square experience. Fluids and Barriers of the CNS 12:O14

6. Chesnut RM, Temkin N, Carney N, Dikmen S, Rondina C, Videtta W, Petroni G, Lujan S, Pridgeon J, Barber J, Machamer J, Chaddock K, Celix JM, Cherner M, Hendrix T (2012) A trial of intracranial-pressure monitoring in traumatic brain injury. N Engl J Med 367:2471-2481

7. Cooper DJ, Rosenfeld JV, Murray L, Arabi YM, Davies AR, D'Urso P, Kossmann T, Ponsford J, Seppelt I, Reilly P, Wolfe R (2011) Decompressive craniectomy in diffuse traumatic brain injury. N Engl J Med 364:1493-1502

8. Eide PK, Fremming AD, Sorteberg A (2003) Lack of relationship between resistance to cerebrospinal fluid outflow and intracranial 
pressure in normal pressure hydrocephalus. Acta Neurol Scand 108:381-388

9. Eide PK, Kerty E (2011) Static and pulsatile intracranial pressure in idiopathic intracranial hypertension. Clin Neurol Neurosurg 113: $123-128$

10. Eide PK, Sorteberg W (2010) Diagnostic intracranial pressure monitoring and surgical management in idiopathic normal pressure hydrocephalus: a 6-year review of 214 patients. Neurosurgery 66:80-91

11. Eide PK, Sorteberg W (2016) Outcome of surgery for idiopathic normal pressure hydrocephalus: role of preoperative static and pulsatile intracranial pressure. World Neurosurgery 86:186-193 e181

12. Fric R, Eide PK (2015) Comparison of pulsatile and static pressures within the intracranial and lumbar compartments in patients with Chiari malformation type 1: a prospective observational study. Acta Neurochir 157:1411-1423 discussion 1423

13. Fric R, Eide PK (2016) Comparative observational study on the clinical presentation, intracranial volume measurements, and intracranial pressure scores in patients with either Chiari malformation Type I or idiopathic intracranial hypertension. J Neurosurg 1-11 https://www.ncbi.nlm.nih.gov/pubmed/27341045

14. Fric R, Eide PK (2016) Perioperative monitoring of pulsatile and static intracranial pressure in patients with Chiari malformation type 1 undergoing foramen magnum decompression. Acta Neurochir 158:341-347 discussion 346-347

15. Fric R, Lindstrom EK, Ringstad GA, Mardal KA, Eide PK (2016) The association between the pulse pressure gradient at the craniocervical junction derived from phase-contrast magnetic resonance imaging and invasively measured pulsatile intracranial pressure in symptomatic patients with Chiari malformation type 1 . Acta Neurochir 158:2295-2304

16. Hutchinson PJ, Kolias AG, Timofeev IS, Corteen EA, Czosnyka M, Timothy J, Anderson I, Bulters DO, Belli A, Eynon CA, Wadley J, Mendelow AD, Mitchell PM, Wilson MH, Critchley G, Sahuquillo J, Unterberg A, Servadei F, Teasdale GM, Pickard JD, Menon DK, Murray GD, Kirkpatrick PJ (2016) Trial of Decompressive Craniectomy for traumatic intracranial hypertension. N Engl J Med 375:1119-1130

17. Matloob SA, Toma AK, Thompson SD, Gan CL, Dyson EW, Craven C, Chari A, Patel NA, Chan HW, Shah S, Haylock-Vize P, Ekanayake J, Robertson F, Thorne L, Watkins LD (2015) Venous sinus stenting immediately reduces intracranial pressure in idiopathic intracranial hypertension patients with venous sinus stenosis. Fluids and Barriers of the CNS 12:062

18. Matloob SA, Toma AK, Thorne L, Watkins LD (2015) Surgically managed idiopathic intracranial hypertension in adults: a single centre experience. Acta Neurochir 157:2099-2103

19. Thompson SD, Coutts A, Craven CL, Toma AK, Thorne LW, Watkins LD (2017) Elective ICP monitoring: how long is long enough? Acta Neurochir https://www.ncbi.nlm.nih.gov/pubmed/? term $=28108854$

20. Toma AK, Tarnaris A, Kitchen ND, Watkins LD (2010) Continuous intracranial pressure monitoring in pseudotumour cerebri: Single centre experience. Br J Neurosurg 24:584-588

21. Toma AK, Tarnaris A, Kitchen ND, Watkins LD (2010) Investigating shunt function using continuous intracranial pressure monitoring in adults: single center experience. J Neurosurg 113: $1326-1330$ 